Research Article

\title{
Impact of Musculoskeletal Dysfunctions on Quality of Life of Pregnant Women
}

\author{
Himanshu Vyas', Deviga T' ${ }^{2}$, Mamta $^{3}$ \\ ${ }^{1}$ Associate Professor, Nursing Superintendent, All India Institute of Medical Sciences (AIIMS), Jodhpur, Rajasthan, India. \\ ${ }^{2,3}$ All India Institute of Medical Sciences (AIIMS), Jodhpur, Rajasthan, India.
}

DOI: https://doi.org/10.24321/2455.9318.202015

I $\quad \begin{array}{lllll}\mathbf{N} & \mathbf{F} & \mathbf{O}\end{array}$

\section{Corresponding Author:}

Himanshu Vyas, Nursing Superintendent, All India Institute of Medical Sciences (AIIMS), Jodhpur, Rajasthan, India.

E-mail Id:

himanshunsg@gmail.com

Orcid Id:

https://orcid.org/0000-0002-2876-1122

How to cite this article:

Vyas H, Deviga T, Mamta. Impact of Musculoskeletal Dysfunctions on Quality of Life of Pregnant Women. Int J Nurs Midwif Res 2020; 7(2): 27-31.

Date of Submission: 2020-07-20

Date of Acceptance: 2020-09-10

\section{$\begin{array}{llllllllll}\mathbf{A} & \mathbf{B} & \mathbf{S} & \mathbf{T} & \mathbf{R} & \mathbf{A} & \mathbf{C} & \mathbf{T}\end{array}$}

Background: Pregnancy is a special condition which is neither a disease nor a normal body status. The anatomical, physiological, and biochemical adjustments are significant during pregnancy, starting soon after fertilization and continuing throughout pregnancy. Reasons for pain during pregnancy include hormonal changes, increased weight, postural variations and impaired strength and co-ordination of abdominal and pelvic muscles. Musculoskeletal pain during pregnancy can have a significant negative impact on day to day functioning.

Objectives: To determine the level of musculoskeletal discomforts in pregnancy, to explore the relationship between the musculoskeletal discomfort and quality of life in pregnancy and to associate the selected demographic variables with musculoskeletal discomfort in pregnancy.

Methods: Cross-sectional research design was used. 323 antenatal mothers, gestational age more than 20 weeks, attending antenatal OPD of a tertiary care hospital of western Rajasthan were selected with the convenient sampling technique. Pregnancy musculoskeletal discomforts were assessed by Pregnancy Induced Musculoskeletal Dysfunctional Scale (PMDS) and quality of life (QOL) was assessed by the WHOQOL-BREF scoring questionnaires. Descriptive and inferential statistics were employed to analyse the data.

Results: Pregnant women reported most frequently the low back pain (60\%) and leg cramps (42\%) and majority of them experienced mild form of pain. Result also showed the number of symptoms increased with progressing trimester. In case of quality of life, less than $50 \%$ of pregnant women reported with average and poor quality of life. The quality of life was found to be negatively correlated with various level of intensity of musculoskeletal pain.

Conclusion: Among various musculoskeletal dysfunctions, low back pain and leg cramp are the most common symptoms of all and it affects the quality of life in pregnancy in different dimensions of health. Considering this aspect would help health care professionals to offer appropriate care and education in view of prevention of musculoskeletal dysfunctions and promote health of mother during pregnancy.

Keywords: Pregnancy, Musculoskeletal discomforts, QOL, PMDS, WHOQOL-BREF 


\section{Introduction}

Pregnancy is a special condition which is neither a disease nor a normal health status. In pregnancy, organic and hormonal variations change the physical performance and mental health in women. These variations might also change women's perception of quality of life. ${ }^{1}$ Pregnant women face multiple musculoskeletal symptoms in second and third trimester of pregnancy. Pain in pregnancy is common concern among $60 \%$ of women globally. ${ }^{2}$ In fact, it is often considered as an inevitable part of pregnancy. ${ }^{3}$ Explanations for pain include hormonal changes, increased weight, postural differences and impaired strength and active co-ordination of abdominal muscles. ${ }^{4,5}$

Yasobant S et al. stated that almost all women experience musculoskeletal discomfort during pregnancy, 55.6\% reported low back pain. ${ }^{6}$ Ramachandra $\mathrm{P}$ et al. reported the most common musculoskeletal dysfunctions among Indian pregnant women are calf muscle cramps, foot pain, low back pain and pelvic girdle pain. Lumbo-pelvic pain ranges from $4 \%$ to $90 \%$ across various studies. ${ }^{7}$ Review of 28 studies found average prevalence of $45 \%$ all pregnant women suffer from pregnancy related to lumbo-pelvic pain/ pregnancy related to low back ache. ${ }^{8}$ Virtually all women experience some degree of musculoskeletal discomfort during pregnancy with approximately $25 \%$ having disabling symptoms. $^{9}$

Most of time pregnancy related musculoskeletal symptoms are considered as a part of pregnancy changes. Until the musculoskeletal symptoms affect activity of daily living, it is not reported widely. Moreover, the information about the changes experienced by pregnant women and its effects are limited. This changeable area in pregnant women requires more attention. It is important to measure pregnancy related symptoms and its effect on the quality of life. So, the present study was conducted to understand the potential relationship between musculoskeletal discomfort and quality of life in pregnancy which would enable health professionals to treat and support pregnant women.

\section{Materials and Methods}

A cross-sectional descriptive research was conducted at antenatal outpatient unit of a tertiary care hospital of western Rajasthan. Antenatal mothers, gestational age more than 20 weeks, attending antenatal OPD were selected by following purposive sampling technique. The sample size of this study was calculated as 323 , by assuming $70 \%$ having maternal musculoskeletal discomfort, with $95 \%$ set interval and 5\% confidence interval. Pregnant women above 20 years of age, gestation age more than 20 weeks, having musculoskeletal discomfort were included. Pregnant women aged more than 35 years, high risk pregnancies and musculoskeletal dysfunctions existing prior to pregnancy were excluded. The study was approved from Institutional Ethics Committee. Informed written consent was obtained from each participant. Confidentiality of information and anonymity of the subjects was maintained.

Data were collected by interview using a data sheet for recording personal variables of pregnant women such as age, educational status, occupation, parity, etc. and the pregnancy related musculoskeletal pains were assessed by Pregnancy Induced Musculoskeletal Dysfunctional Scale (PMDS). It comprising of 16 items: neck pain, upper back pain, rib pain/soreness, carpal tunnel syndrome, low back pain, symphysis pubis pain, pelvic girdle pain, coccyx pain, hip pain, knee pain, ankle pain, foot pain, lower limb tingling/numbness, pedal oedema, leg cramp, abdominal cramp. These discomforts were assessed with intensities and frequencies. Intensity and ADL interference were interpreted follows: 1-Absent: The discomfort has not been experienced, 2-Mild: The discomfort was barely noticeable, 3-Moderate: The discomfort was noticeable but did not interfere with your daily activities, 4-Severe: The discomfort was very noticeable and interfered with your daily activities. Future, the total number of symptoms were categorized into very low (0-4 no.), low (5-8 no.), moderate (9-12 no.) and high (13-16 no.) number of symptoms.

The quality of life was assessed by WHO-QOL-BREF Scoring questionnaire. It includes four domain scores and two individually scored items about an individual's overall perception of quality of life and health. It include 26 items First two items in general, 7 items related to physical domain, 6 items related to psychological domain, 3 items related to social relationship and 8 items related to environment. The raw scores were converting into transformed score (0-100). The questions were scored with $1=$ very poor, 2 = poor, 3 = neither poor nor good, 4 = good and 5 = very good. The transformed score (0-100) was then graded for the quality of life: Low QOL (0-32 score), Moderate QOL (33-65 score) and Good/High QOL (66-100 score). Data were analysed using SPSS 16 version descriptive statistics were employed. Spearman's correlation coefficient was computed to determine the relationship between the musculoskeletal discomfort and quality of life. Chi-square test was done to determine the association between the musculoskeletal discomforts with selected demographic variables.

\section{Result}

A total of 323 participants in the age group of 20-35 years who visited antenatal OPD were enrolled for the study period. All subjects were interviewed to complete questionnaires. 
Table I.Frequency distribution of demographic variables of subjects

$(n=323)$

\begin{tabular}{|c|c|c|}
\hline Demographic variables & Frequency & Percentage \\
\hline \multicolumn{3}{|l|}{ Age } \\
\hline $20-25$ years & 180 & 55.7 \\
\hline $26-30$ years & 132 & 40.9 \\
\hline $31-35$ years & 11 & 3.4 \\
\hline \multicolumn{3}{|l|}{ Education } \\
\hline Primary & 118 & 36.5 \\
\hline Secondary & 112 & 34.7 \\
\hline Higher secondary & 36 & 11.1 \\
\hline Degree and above & 57 & 17.6 \\
\hline \multicolumn{3}{|l|}{ Occupation } \\
\hline Unemployed & 281 & 87 \\
\hline Employed & 42 & 13 \\
\hline \multicolumn{3}{|l|}{ Type of family } \\
\hline Nuclear & 121 & 37.5 \\
\hline Joint & 202 & 62.5 \\
\hline \multicolumn{3}{|l|}{ Religion } \\
\hline Hindu & 295 & 91.3 \\
\hline Muslim & 26 & 8 \\
\hline Christian & 0 & 0 \\
\hline Others & 2 & 0.6 \\
\hline \multicolumn{3}{|l|}{ Gravida } \\
\hline Primi & 212 & 65.6 \\
\hline Multi & 111 & 34.4 \\
\hline
\end{tabular}

Table 1, shows that majority $55.7 \%$ (180) belongs to the age group of $20-25$ years, $36.5 \%$ (118) have primary education, $87 \%$ (281) were unemployed, $62.5 \%$ (202) were from Joint family, $91.3 \%$ belongs to Hindu religion, and $65.6 \%$ (212) were Primi Gravida.

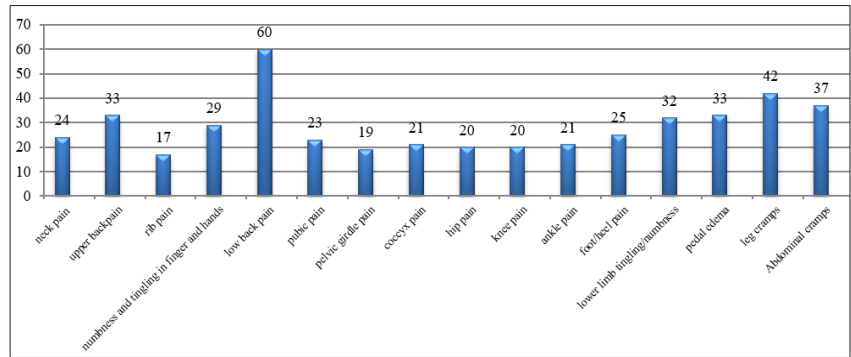

Figure I.Percentage distribution of individual musculoskeletal discomforts

Figure 1, shows that most common musculoskeletal pains were low back pain 193 (60\%), Leg cramps 135 (42\%). abdominal cramps 118 (37\%), upper back pain 107 (33\%), pedal oedema 107 (33\%) and lower limb tingling/numbness $103(32 \%)$.

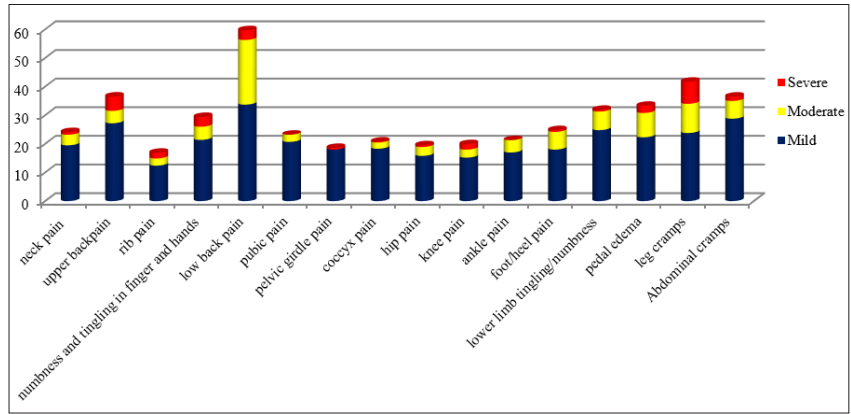

Figure 2.Musculoskeletal Discomforts of Subjects in Percentage

Figure 2, shows that the majority of pregnant women with musculoskeletal pain reported mild level of pain. Only few participants were reported severe level of musculoskeletal pain.

Table 2.Number of musculoskeletal discomforts in percentage

$(n=323)$

\begin{tabular}{|c|c|c|c|}
\hline $\begin{array}{c}\text { Number of } \\
\text { musculo- } \\
\text { skeletal } \\
\text { discomforts }\end{array}$ & $\begin{array}{c}\text { Total } \\
\text { percentage }\end{array}$ & $\begin{array}{c}\mathbf{2}^{\text {nd }} \\
\text { trimester } \\
\mathbf{( \% )}\end{array}$ & $\begin{array}{c}\mathbf{3}^{\text {rd }} \\
\text { trimester } \\
(\%)\end{array}$ \\
\hline Very low & 60.8 & 60 & 61 \\
Low & 23.2 & 19 & 24 \\
Moderate & 11.5 & 16 & 11 \\
High & 4.3 & 5 & 4 \\
\hline
\end{tabular}

Table 2, shows the number of musculoskeletal discomforts; Very low (<4) was $61.0 \%$ (197), Low (5- 8) was $23.2 \%$ (75), Moderate (9-12) 11.5\% (37), High (13-16) was 4.3\% (14). Majority had less number of musculoskeletal discomforts and few had high number of musculoskeletal discomforts.

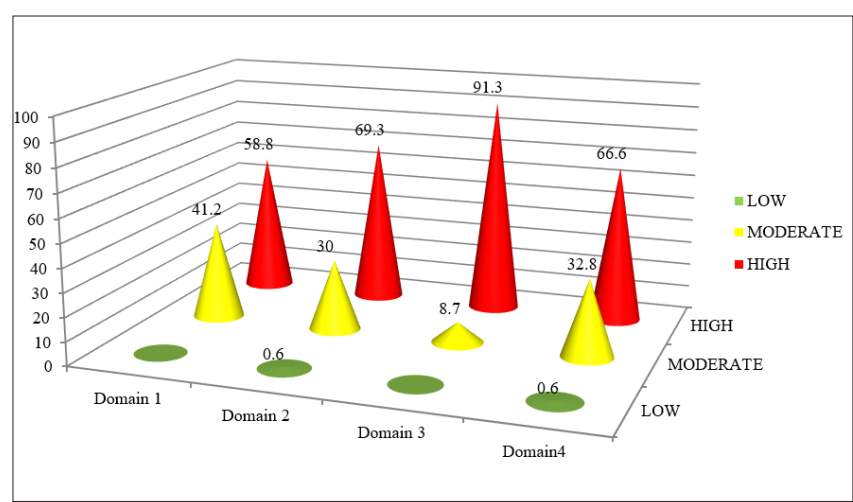

Figure 3.Quality of life in percentage

Figure 3, shows subjects' quality of life (QOL) in percentage. In domain 1 (physical health) 58.8\% had high QOL and $41.2 \%$ 
had moderate QOL. In domain 2 (Psychological) 69.3\% had high QOL and 30\% had moderate QOL. In domain 3 (Social relationship) $91.3 \%$ had high QOL and $8.7 \%$ had moderate QOL. In domain 4 (Environment) 66.6\% had high QOL and $32.8 \%$ had moderate QOL.
33\%). Majority musculoskeletal discomforts were reported in third trimester when compared to second trimester.

Abbaszadeh et al. report that women's vitality is reduced during pregnancy, leading to a decrease in quality of life

Table 3.Correlation between the intensity of musculoskeletal discomforts and quality of life

\begin{tabular}{|c|c|c|c|c|}
\hline $\begin{array}{l}\text { Musculoskeletal } \\
\text { discomfort Intensity }\end{array}$ & $\begin{array}{c}\text { Domain } 1 \\
\text { (physical health) }\end{array}$ & $\begin{array}{c}\text { Domain } 2 \\
\text { (Psychological) }\end{array}$ & $\begin{array}{c}\text { Domain } 3 \\
\text { (Social relationship) }\end{array}$ & $\begin{array}{c}\text { Domain } 4 \\
\text { (Environment) }\end{array}$ \\
\hline $\begin{array}{l}\text { Total number of } \\
\text { discomforts }\end{array}$ & $\begin{array}{c}r=-0.393^{* *} \\
p=0.000\end{array}$ & $\begin{array}{c}r=-0.409 * * \\
p=0.000\end{array}$ & $\begin{array}{c}r=-0.208^{* *} \\
p=0.000\end{array}$ & $\begin{array}{c}r=-0.348^{* *} \\
p=0.000\end{array}$ \\
\hline Mild & $\begin{array}{c}r=-0.384^{* *} \\
p=0.000\end{array}$ & $\begin{array}{c}r=-0.378^{* *} \\
p=0.000\end{array}$ & $\begin{array}{c}r=-0.378 * * \\
p=0.000\end{array}$ & $\begin{array}{c}r=-0.351^{* *} \\
p=0.000\end{array}$ \\
\hline Moderate & $\begin{array}{c}r=-0.231^{* *} \\
p=0.000\end{array}$ & $\begin{array}{c}r=-0.200 * * \\
p=0.000\end{array}$ & $\begin{array}{c}r=-0.200 * * \\
p=0.000\end{array}$ & $\begin{array}{c}r=-0.121^{*} \\
p=0.030\end{array}$ \\
\hline Severe & $\begin{array}{l}r=0.009 \\
p=0.874\end{array}$ & $\begin{array}{l}r=0.036 \\
p=0.522\end{array}$ & $\begin{array}{l}r=0.036 \\
p=0.522\end{array}$ & $\begin{array}{c}r=-0.155^{* *} \\
p=0.005\end{array}$ \\
\hline
\end{tabular}

** Correlation at the 0.001 level ( 2 tailed); *Correlation at the 0.05 level ( 2 tailed).

Table 3, shows that the total number of discomfort, mild and moderate intensity of discomforts negatively correlated with all four domains of health. But, In case of severe intensity of discomforts were negatively correlated only with environment health domain. This may be due to few numbers of participants with severe intensity form of symptoms.

Table 4.Association of musculoskeletal discomforts with selected demographic variables

\begin{tabular}{|c|c|c|}
\hline Demographic variables & Chi-square value & P-value \\
\hline Age group & 6.997 & 0.274 \\
\hline Education & 6.388 & 0.699 \\
\hline Occupation & 2.130 & 0.550 \\
\hline Type of family & 0.237 & 0.977 \\
\hline Religion & 10.874 & $0.05^{*}$ \\
\hline Gravida & 0.804 & 0.849 \\
\hline
\end{tabular}

*Association at the 0.05 level ( 2 tailed).

Table 4, shows that there is no significant association between socio-demographic variables and category of musculoskeletal discomforts except religion.

\section{Discussion}

Prabha S et al. stated that the most common pregnancy musculoskeletal discomforts are low back pain, pelvic girdle pain, leg cramps and pedal oedema. Further study showed that low back pain $32 \%$ in second trimester increased to $45 \%$ in third trimester and leg cramps in $18 \%$ in second trimester increased to $26 \%$ in third trimester. ${ }^{10}$ Similarly, in our study, the more prevalent discomforts are lower back pain $(n=193$, $60 \%)$, leg cramps ( $n=135,42 \%)$ and pedal oedema $(n=107$, even during normal pregnancy. ${ }^{11}$ In the present study as well the physical health aspects showed $58.8 \%$ of good quality of life, $41.2 \%$ moderate quality of life. Psychological aspects showed $69.3 \%$ of good quality of life, $30 \%$ moderate quality of life. Social relationship showed $91.3 \%$ of good quality of life and $8.7 \%$ of moderate quality of life. Environment health showed $66.6 \%$ good quality of life and $32.8 \%$ moderate quality of life. Poor quality of life showed $0-0.6 \%$ in all four dimensions of health.

The majority of women consider their discomforts as a part of gestational change unless its severity affects their daily routine activities. Moreover the perception of pain remains subjective. Yasobant S et al. identify, as the pain increases the disability too occurs during daily activities, which results in poor quality of life. 6 In the current study, number of symptoms, mild and moderate intensity of discomforts negatively correlated with all four domains of health. It reflects the musculoskeletal discomforts are affecting their overall health quality of life of pregnancy.

\section{Conclusion}

Low back pain, leg cramps and pedal oedema are the most common complaints in pregnancy and the musculoskeletal discomfort intensity increased with progressing trimester. Further, the musculoskeletal discomforts affect the quality of life of pregnancy in all four health dimensions i.e. physical health, psychological, social relationship and Environment. Consideration of these pregnancy discomforts would help health care professionals to offer appropriate therapy in view of prevention of ill-health and health promotion of antenatal women.

\section{Conflict of Interest: None}




\section{References}

1. Forger F, Ostensen M, Schumacher A et al. Impact of pregnancy on health related quality of life evaluated prospectively in pregnant women with rheumatic diseases by the SF-36 health survey. Ann Rheum Dis 2005; 64(10): 1494-1499.

2. Martin CR, Jomeen J. Assessment of quality of life during pregnancy and in the postnatal period. In: Preedy V, Watson R, editors. Handbook of Disease Burdens and Quality of Life Measures. Springer, New York. 2010, pp.2411-22.

3. Bastiaanssen JM, de Bie RA, Bastiaenen $\mathrm{CH}$ et al. A historical perspective on pregnancy-related low back and/or pelvic girdle pain. European Journal of Obstetrics and Gynaecology and Reproductive Biology 2005; 120: 3-14.

4. Mogren I, Pohjanen A. Low back pain and pelvic pain during pregnancy: prevalence and risk factors. Health Services Research 2005; 30: 983-991.

5. MacLennan AH, Nicolson R, Green Cet al. Serum relaxin and pelvic pain of pregnancy. Lancet 1986; 2: 243-245.

6. Yasobant S, Nibedita S, Saswata S et al. Musculoskeletal problems among pregnant women: a facility based survey in Odisha. International Journal of Medical Research and Health Sciences 2014; 3(2): 358-363.

7. Preetha Ramachandra, Maiya AG, Pratap K. Prevalence of musculoskeletal dysfunctions among Indian pregnant women. Journal of Pregnancy 2015; 1-4.

8. Wu WH, Meijer OG, Uegaki K et al. Pregnancy related pelvic girdle pain (PPP), I: Terminology, clinical presentation, and prevalence. European Spine Journal 2004; 13(7): 575-589.

9. Borg-Stein J, Dugan SA. Musculoskeletal disorders of pregnancy, delivery and postpartum. Phys Med Rehabil Clin N Am 2007; 18(3): 459-476.

10. Sathyaprabha B, Jayavijayaraghavan, Maiya AG et al. Pregnancy induced musculo skeletal dysfunction scaledevelopment and validation. Indian Journal of Public Health Research and Development 2017; 8(3): 347-350.

11. Abbaszadeh F, Bagheri A, Mehran N. Quality of life among pregnant women. J Hayat 2009; 15(1): 41-48. 